\title{
Comparing Japan's Lost Decade with the U.S. Great Recession
}

\author{
Guillaume Vandenbroucke, Research Officer
}

apan's economy began its "Lost Decade" in the 1990s, with persistent slow growth and low inflation. One could argue, however, that the Lost Decade has persisted for nearly three decades.

In 2008, the United States entered into what is now called the "Great Recession." The Great Recession was also characterized by slow growth and low inflation. These similarities between the Lost Decade and the Great Recession have led many analysts to wonder whether the United States is in for the same persistent economic slump as Japan.

\section{Is the United States headed for a "lost decade" similar to Japan's?}

In this analysis it is critical to draw a distinction between a change in the growth rate of gross domestic product (GDP) per capita and a change in its level. For instance, a country can experience a sudden decline in the level of its GDP per capita after a major recession, but its growth rate can remain constant. Conversely, a country's rate of growth can decline without any sudden drop in the level of its GDP per capita. The Japanese data reveal that the Lost Decade is clearly a case of slow growth rather than of a sudden negative shock to GDP per capita. The U.S. data, slightly varied, reveal that the Great Recession is the opposite case.

Figure 1 shows real GDP per capita in the United States in 2010 dollars. The dotted trend line extending past 2007 reflects an out-of-sample prediction for the years 2008-2016, computed using the data available in 2007. Figure 2 displays the same information for Japan, although the trend was computed using pre-1990 data. The main takeaway from a comparison of these two graphs is the different nature of the behavior of GDP per capita after 2007 for the United States and after 1990 for Japan.

U.S. GDP per capita clearly dropped below its trend after 2007, but the shock was mostly to the level of GDP per capita, not so much to its rate of growth. (The growth rate of GDP, on these graphs, is measured by the slope of

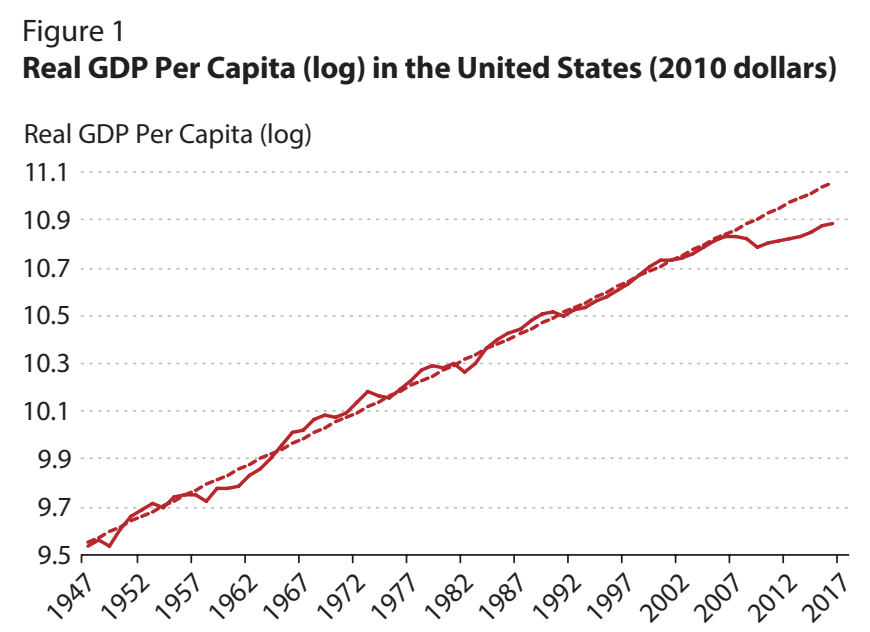

SOURCE: Bureau of Economic Analysis and Census Bureau.

\section{Figure 2}

Real GDP Per Capita (log) in Japan

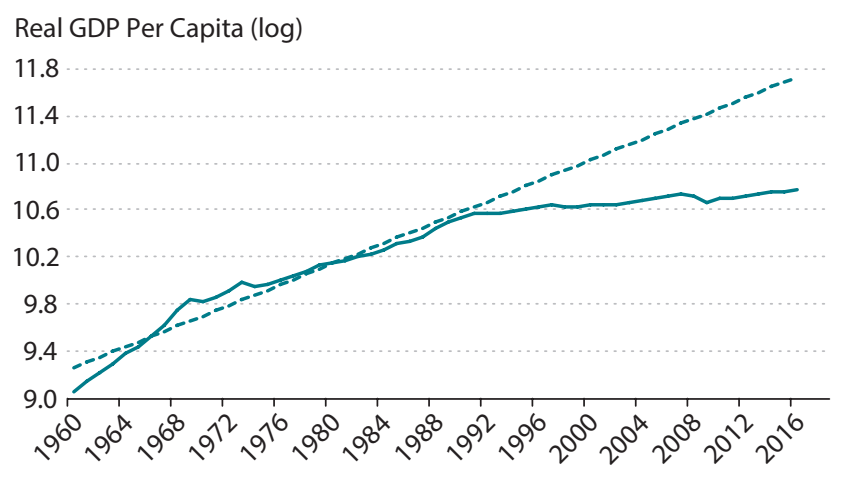

SOURCE: University of Groningen.

the solid line.) To be precise, it is also true that the rate of growth was slower after 2007 than before, but the difference is relatively small compared with what happened in Japan during the 1990s. To see this, consider Figure 2.

In Japan, there was no sudden drop in the level of GDP per capita in 1990. The growth rate, however, dropped considerably. And, as can be seen, GDP has been relatively stable since the early 1990s. The difference between actual 
Japanese GDP per capita and the trend represented by the dotted line grows every year.

To gauge the importance of the distinction between level and growth-rate effects, consider the following question: How long does it take for GDP per capita to double? In the United States prior to 2007, the average growth rate was such that GDP per capita doubled about every 32 years. After the sudden drop in GDP per capita in 2007, the new growth rate is slightly less than before, implying that GDP per capita will double every 50 years if it does not accelerate or slow down significantly. Thus, it now takes 56 percent more time for GDP per capita to double in the United States than it took before the Great Recession. What of Japan? Before 1990, the average growth rate was such that GDP per capita doubled every 14 years. The post-1990 growth rate implies, however, that it will take 80 years for GDP per capita to double in Japan: That's 470 percent more time than before! 